\title{
Los grandes en un mercado de chicos. El abasto de carne en Buenos Aires colonial.
}

Resumen: Se ha demostrado que el abasto de carne a la ciudad de Buenos Aires tardocolonial es un mercado diversificado en el que predominan los medianos y pequeños productores y comercializadores, donde las pequeñas transacciones modelan una demanda constante y sistemàtica. Sin embargo, en ese universo se presenta un reducido grupo de "grandes productores" y "grandes abastecedores", que lo matizan. Grupo que aparece en los corrales de abasto citadino con un promedio que excede las 100 vacunos mensuales, destacándose del resto. En el presente estudio intentamos profundizar la identidad de estos actores sociales, teniendo como objetivo principal su identificación a través del estudio de sus características, puntos de acercamiento, asì como su incidencia dentro de este mercado local y de la economía tardo-colonial de Buenos Aires en su conjunto.

Palabras claves: mercado de abasto- carne vacuna -grandes abastecedores - grandes productores

\begin{abstract}
It has been shown that the meat supply to the city of Buenos Aires latecolonial is a diversified market where small and medium producers and marketers where small transaction model a constant and systematic demand predominate. However, in this universe is presented a small group of "large producers" and "major suppliers" that qualify this universe. Group listed on citadino pens cope with an average monthly exceeding 100 cattle, highlighting the rest. In the present study we try to the identity of these actors, with the main objective identification through the study of their characteristics, approach points and incidence in this local market and late-colonial economy of Buenos Aires as a whole
\end{abstract}

Keywords: Suply market - beef - large suppliers -large producers

\footnotetext{
* Profesora y Magister Artis en Historia. Docente e Investigadora de Universidad Nacional de Mar del Plata - Grupo de Investigación: Problemas y Debates del siglo XIX - CEHIS - Dpto. de Historia Facultad de Humanidades - Universidad Nacional de Mar del Plata - mail: aldupuy@mdp.edu.ar
} 


\section{Revista Brasileira de História \& Ciências Sociais - RBHCS}

Vol. 8 No $^{\circ}$ 16, Julho - Dezembro de 2016

\section{Introducciòn}

En el Río de la Plata la carne era un producto básico en la dieta de la población. Había llegado de mano de los españoles y desde los tiempos de la conquista formaba parte de las costumbres alimentarias cotidianas. En Buenos Aires (como las tierras del Litoral aledaño), la producción de carne vacuna se veía estimulada por la amplia disponibilidad de tierras sumamente aptas para la actividad agrícola-ganadera, así como la baja tecnología que esta producción implicaba, lo que se traducía en una producción que, en términos generales, implicaba bajos costos.

De esta manera, desde el siglo XVI la producción y el consumo de carne formaba parte de los alimentos básicos cotidianos. Desde el primer momento y hasta mediados del siglo XVIII la provisión de este alimento estuvo a cargo de un hacendado reconocido, el “obligado", asentado en la institución del estanco regulada por el Ayuntamiento.

Después de un siglo relativamente estable, ya en el XVIII, aparece un Buenos Aires colonial en el que se manifiestan cambios graduales como el crecimiento sistemático de las exportaciones pecuarias, la expansión de la frontera en busca de nuevas tierras de asentamiento y producción, un crecimiento demográfico constante y creciente y un intercambio cada vez más vigoroso entre la ciudad y la campaña. En correlato, el habitual consumo de carne comienza a acrecentarse y dinamizarse y la modalidad de provisión debe adaptarse a las nuevas circunstancias.

De esta manera, a partir de la mitad del siglo XVIII, una nueva forma de abastecimiento de carne para el consumo viene a modificar sustancialmente la forma de provisión tradicional que se llevaba a cabo a través de la institución del estanco.

En esta nueva modalidad aparecieron junto al representante del Cabildo, el Fiel Ejecutor, dos actores sociales fundamentales, los productores y los abastecedores, que le imprimieron una característica propia a este mercado.

Precisamente, los estudios que hemos realizado en estos últimos años, referidos al mercado de abasto de carne para consumo en la ciudad de Buenos Aires colonial han mostrado una comercialización básicamente atomizada, diversificada. Quienes controlan el circuito de producción -comercializaciòn son predominantemente productores $\mathrm{y}$ abastecedores muy pequeños, pequeños y medianos ${ }^{1}$.

${ }^{1}$ DUPUY, A, Mercado de abasto de carne en Buenos Aires colonial (siglos XVI- XVIII), Cambios y continuidades, Madrid, Editorial Académica Española, 2013. 


\section{Revista Brasileira de História \& Ciências Sociais - RBHCS}

Vol. $8 \mathrm{~N}^{\mathrm{O}}$ 16, Julho - Dezembro de 2016

Sin embargo, en ese universo tan atomizado se ha podido detectar a un muy reducido grupo de "grandes productores" y "grandes comerciantes abastecedores", (diferentes de aquellos obligados), quienes aparecen en forma sistemática, matizando esa imagen de un mercado local fragmentado.

Ciertamente, un muy reducido grupo de productores, dentro de los hacendados reconocidos en la sociedad rioplatense colonial, envía una cantidad de reses destinadas al consumo que se muestra relacionalmente significativa, entrando dentro del grupo de los "grandes" aquellos productores ganaderos que se registran con un ingreso promedio de más de 100 vacunos mensuales en los corrales de abasto urbano.

Por su parte, también un sector de comerciantes, los abastecedores-intermediarios que llegan a los corrales con grandes cantidades de reses marcadas (un promedio de más de 100 vacunos mensuales) es mínimo pero se destaca del resto.

Precisamente, en el presente trabajo intentaremos ahondar la identidad de este número reducido de actores sociales que hemos denominado los "grandes". El objetivo principal es poder identificar sus características, puntos de acercamiento, así como su incidencia dentro de este mercado local.

Las fuentes con las que se ha trabajado han sido los registros inéditos de entrada de ganado a los corrales de Carricaburu del periodo 1776 a 1786 que se encuentran en el $\mathrm{AGN}^{2}$. Asì como las Actas de Cabildo èditas de los cuatro últimos meses de $1782 \mathrm{y}$ el año 1783. También las Actas de Cabildo correspondientes al siglo XVIII pertenecientes a la sección de Abastos3.

Finalmente, se abordó el estudio de los Padrones de 1726 y 1744 del partido de Magdalena así como Testamentarias y Actas de bautismo del Partido de Quilmes, que nos permitió tener una visión más clara de los principales protagonistas de este mercado4.

${ }^{2}$ Archivo General de la Nación: Sala IX, 20-1-3

3Actas del Extinguido Cabildo, sección: Abastos, 20-7-170:1773. ACTAS del Extinguido Cabildo de Buenos Aires : Serie III - Tomo IX - Libros XLIX - L -LI-LII. Años: 1789-1791, 1931; - Actas del Extinguido Cabildo : Serie III - Tomo XI - Libros LIV a LVII. Años 1796-18oo; 1933; Actas del Extinguido Cabildo: Serie IV; Tomo III -Libros LXII - LXIII y LXIV. Bs. As. Años: 1808 - 1809, 1928.

4 CALVO, C, Familias argentinas, en: Instituto de Ciencias Genealógicas, Tomo XI, nro.151, p.151, 1980; . 
Revista Brasileira de História \& Ciências Sociais - RBHCS

Vol. $8 \mathrm{~N}^{\mathrm{O}}$ 16, Julho - Dezembro de 2016

\section{1.'QQUIENES SON LOS GRANDES PRODUCTORES DEL MERCADO LOCAL DE ABASTO DE CARNE PARA EL CONSUMO?}

El mercado de abasto de carne a la ciudad de Buenos Aires está estructurado en función a un circuito de producción-comercialización donde las pequeñas transacciones son predominantes 5 . En este sentido, en términos generales, los productores envían al mercado, para todo el último cuarto del siglo XVIII, un promedio de 76,4 reses mensuales per capita, lo que indicaría un promedio diario de 3,8 reses por productor. Asimismo, se observa que el $87,4 \%$ de estos productores aparece enviando mensualmente menos de 50 vacunos para el periodo tardo-colonial. Por su parte, los "grandes" productores, llamados así porque envían más de 100 vacunos mensuales, conforman un porcentual proporcionalmente menor, puesto que representan el 1,4\% del total de productores que destinan ganado vacuno al abasto de Buenos Aires. Esto puede verse en el siguiente cuadro:

\section{Cuadro I}

Distribución de frecuencia de reses mensuales ingresadas por los productores (1776 1786)

\begin{tabular}{|l|l|l|l|l|}
\hline Años & $\begin{array}{l}\text { O-49 reses } \\
\text { Porc. }\end{array}$ & $\begin{array}{l}50-99 \text { reses } \\
\text { Porc. }\end{array}$ & $\begin{array}{l}\text { 100-149 } \\
\text { reses } \\
\text { Porc. }\end{array}$ & $\begin{array}{l}+ \text { de 150 } \\
\text { reses Porc. }\end{array}$ \\
\hline 1776 & $89,6 \%(165)$ & $4,3 \%(8)$ & $3,3 \%(6)$ & $2,8 \%(5)$ \\
\hline 1777 & $86,7 \%(228)$ & $9,5 \%(25)$ & $2,3 \%(6)$ & $1,5 \%(4)$ \\
\hline 1778 & $88,6 \%(125)$ & $15,5 \%(25)$ & $4,9 \%(8)$ & $2,5 \%(4)$ \\
\hline 1779 & $87,6 \%(162)$ & $10,3 \%(19)$ & $2,1 \%(4)$ & $0,5 \%(1)$ \\
\hline 1780 & $75 \%(132)$ & $17 \%(30)$ & $5,7 \%(10)$ & $2,3 \%(4)$ \\
\hline 1781 & $91,5 \%(206)$ & $5,8 \%(13)$ & $1,8 \%(4)$ & $0,9 \%(2)$ \\
\hline 1782 & $86 \%(166)$ & $9,3 \%(18)$ & $3,6 \%(7)$ & $1 \%(2)$ \\
\hline 1783 & $86 \%(157)$ & $9,6 \%(18)$ & $4,8 \%(9)$ &, $1 \%(4)$ \\
\hline 1784 & $96,3 \%(310)$ & $3,1 \%(10)$ & $0,3 \%(1)$ & $0,3 \%(1)$ \\
\hline 1785 & $87,3 \%(200)$ & $10 \%(23)$ & $1,7 \%(4)$ & $0,9 \%(2)$ \\
\hline 1786 & $90,7 \%(234)$ & $5,8 \%(15)$ & $1,9 \%(5)$ & $1,5 \%(4)$ \\
\hline Total & $\begin{array}{l}87,4 \% \\
(2085)\end{array}$ & $8,5 \%(204)$ & $2,7 \%(64)$ & $1,4 \%(33$ \\
\hline
\end{tabular}

Fuentes: AGN, Sala IX, 20-1-3.

5 DUPUY, A, Productores y abastecedores en el mercado de abasto de carne a la ciudad de Buenos Aires tardo-colonial, en: III Congreso Latinoamericano de Historia Económica y XXIII Jornadas de Historia Económica - Bariloche, 2012. 


\section{Revista Brasileira de História \& Ciências Sociais - RBHCS}

Vol. $8 \mathrm{~N}^{0}$ 16, Julho - Dezembro de 2016

Las fuentes entonces, revelan que son sólo unos pocos quienes envían un promedio que excede las 100 reses mensuales. Precisamente, la característica particular de un mercado de pequeñas transacciones y diversificado, nos llevó a detener nuestra mirada en quienes constituyen la excepción, aquellos estancieros que conformaban ese reducido grupo de "grandes" productores, cuyos nombres se manifiestan como hacendados reconocidos en la sociedad colonial rioplatense.

De estos "grandes productores" en nuestra muestra de abasto urbano hemos podido detectar cuatro importantes hacendados, a saber, Gabriel Rocha, Januario Fernández, Bartolomé Villoldo y los hermanos Carmona, Martín y Marcos.

\section{1.a. Gabriel Rocha:}

"Hacendado de Fontezuelas del Partido de Pergamino", constituye un reconocido vecino pergaminense que se dedica a la actividad ganadera. Productor de ganado y abastecedor del mercado de abasto de Buenos Aires, con propiedades en Pergamino, constituye la figura emblemática del "gran hacendado" de un partido del norte de la campaña bonaerense. Es hijo de un matrimonio español conformado por el hacendado Don Antonio Rocha y Bernarda Cárdenas, quien es hija de otro destacado hacendado español de fines de siglo, Anselmo Cárdenas ${ }^{6}$.

Gabriel Rocha ha nacido en Pergamino y a fines del siglo XVIII contrae matrimonio con María de la Cruz Ludueña, hija de otra familia de antigua data del lugar, cuyo padre pertenece al grupo de soldados que llegan al fuerte a mediados de siglo y terminan afincándose en esta localidad7.

En el matrimonio que conforman Gabriel Rocha y Marìa de la Cruz Ludueña puede verse la alianza entre familias de hacendados y militares del primer asentamiento que se establecen en tierras realengas y comienzan a dedicarse a la actividad ganadera. De

${ }^{6}$ Cabe destacar que en el Registro de Hacendados de la Jurisdicción de Pergamino para el año 1789, Antonio Rocha figura como uno de los "hacendados asentados en tierras realengas", ya para este año viudo de doña Bernarda Cárdenas, aparece registrado con dos hijos (uno de los cuales es Gabriel y la otra una niña), destacándose por poseer una mulata esclava con tres hijos así como un capital en ganado de 400 vacas, 100 yeguas y 100 ovinos (AGN, Sala IX 9-7-7, Padrones de la ciudad y campaña, 1782-1807) 7 María de la Cruz Ludueña es hija de Alexo Ludueña, quien en el Registro de Comandancia de fronteras de Pergamino correspondiente al año 1778 figura ya como vecino de Pergamino (AGN, Sala IX, 9-7-7Comandancia de Fronteras de Pergamino, 1766-1808) 


\section{Revista Brasileira de História \& Ciências Sociais - RBHCS}

Vol. $8 \mathrm{~N}^{\mathrm{O}}$ 16, Julho - Dezembro de 2016

hecho, al momento del matrimonio cada familia contribuye, entre otros bienes, con ganado en pie ${ }^{8}$.

Las fuentes revelan que el tronco familiar está compuesto por Don Gabriel y su esposa, María de la Cruz y seis hijos Felipe, Paulino, Juan, Pedro, Pascual, Pedro José y María del Socorro.

Las relaciones sociales así como el patrimonio material de Gabriel Rocha le otorgan un papel prestigioso en la comunidad. De hecho, al momento de su fallecimiento en 1818 , su capital estaría conformado por: “... una casa .... Una 'gran estancia ganadera', dinero en efectivo en Buenos Aires bajo documento por un total de \$700-, una casa en el pueblo, más de 1500 cabezas de ganado vacuno, alrededor de 1000 cabezas de ganado lanar, así como cerca de 500 yeguas, 100 potros, 300 potrancas y potrillos y 100 caballos" (TESTAMENTARIA Nro. 5592, Legajo 52 Nro.22, caratulada Gabriel Rocha). Por su parte, posee vínculos amicales y parentales con otros hacendados relacionados con la exportación de cueros como Estanislao Peña o Pedro Domínguez.

Por su parte, Gabriel Rocha muere joven dejando a sus hijos con minoría de edad. Pero, conforme los hijos van haciéndose adultos van recibiendo la parte estipulada por su padre en la testamentaria y parte de ellos se dedicará a la producción agropecuaria. El hijo mayor de Gabriel Rocha, Felipe, siguiendo la tradición familiar se halla registrado en los padrones de 1836 y 1838 como cabeza de estancia, con esclavos y agregados. También aparece en estos padrones otro hijo, Paulino quien siguiendo las costumbres de enlaces dentro del mismo grupo se muestra casado con Juana Rivera hija de otro importante estanciero de Pergamino y estarà consignado en 1836 con estancia y esclavos.

Tanto Felipe como Paulino se presentan en el Partido de Pergamino como testigos de casamiento y padrinos en bautismos, lo que los posiciona como vecinos destacados en la comunidad.

Asimismo, en las fuentes se muestra consignada la estancia de Gabriel Rocha, emplazada en la parte septentrional del partido de Pergamino. Este hacendado y productor para el

\footnotetext{
8 Cabe aclarar que la contribución con ganado a una nueva familia por parte de los padres constituía una práctica común en la colonia. "Las dotes, cuando existían, eran limitadas a unos pocos ítems: algo de ganado, unas pocas prendas, otras posesiones personales y quizás algunas tierras o un esclavo" (MAYO, C, 1995,p.56)
} 


\section{Revista Brasileira de História \& Ciências Sociais - RBHCS}

Vol. 8 No $^{\circ}$ 16, Julho - Dezembro de 2016

mercado de Buenos Aires, figura como uno de los primeros habitantes del paraje designado como Arroyo del Medio o cuartel Nro.3 . Esta estancia posee 2750 varas de frente sobre el arroyo y 9000 varas de fondo. Con respecto a la riqueza del ganado, la misma está conformada por 1106 cabezas de ganado vacuno, 545 ovejas grandes, 203 ovejas chicas y 203 yeguas. Como toda gran estancia tardo-colonial posee un significativo número de esclavos y mano de obra asalariada.

Consecuentemente, Gabriel Rocha es parte de la elite local que accede a los distintos ámbitos del poder político. Su amplio ámbito de sociabilidad lo acercan a los hacendados del partido, quienes tienen sus intereses puestos en el mercado de exportación de cueros. Tales como Don Pedro Domínguez quien además es pariente de su esposa o Gonzalo Guardiola y Santiago Sosa.

Gabriel Rocha y luego sus hijos constituyen importantes proveedores sistemàticamente de ganado para el mercado local, la que complementan con la producción de cueros para el mercado externo.

\section{1.b. Januario Fernández}

Januario Fernández era un hacendado del partido de Magdalena donde fue un reconocido vecino en su comunidad, cuya producción vacuna tenía como principal destino la exportación, pero también envía ganado al mercado de abasto de Buenos Aires. Este hacendado llega a estas tierras desde Lugo en España a Buenos Aires en 1739 y 7 años después se casa con María Ignacia Echeverría, hija de un capitán quipuzcoano establecido en Buenos Aires, Nicolás Echeverría y Eijó y de una descendiente en línea directa de conquistadores y primeros pobladores de Buenos Aires, la familia Rodriguez de Figueroa y Arias. Efectivamente, Januario Fernández es en la etapa colonial uno de los más acaudalados y de renombre con estancia poblada en Magdalena, suma a la muerte de su suegro en 1752, una estancia denominada "Rincón de los Santos" en el Pago de Magdalena, con una superficie aproximada de 100 leguas cuadradas. Siendo Alcalde de la Hermandad edificó con su propio patrimonio la capilla y luego la Iglesia del pago.

Si bien el mercado prioritario de su producción es el de exportación de cueros, parte de su ganado es destinado al mercado de abasto local.

\section{1.c. Bartolomé Villoldo}




\section{Revista Brasileira de História \& Ciências Sociais - RBHCS}

Vol. 8 No $^{\circ}$ 16, Julho - Dezembro de 2016

Bartolomé Villoldo, forma parte de una familia de estancieros arraigada desde principios del siglo XVIII en Magdalena y es descendiente de otro importante estanciero del partido como fue Juan Rodolfo Villoldo. Durante los años que estamos analizando Don Bartolomé residía junto a su familia en una casa de la ciudad, no así en la estancia de Magdalena. Lo que hace pensar que era un hacendado instalado en Buenos Aires que producía bienes rurales para los distintos ámbitos del mercado. Se lo ve, en los registros de entrada de corrales, enviando una gran cantidad de reses mensuales que permite considerarlo como gran productor de ganado para el abasto porteño con conexiones directas con los mercados que lo conectan con la exportación de cueros.

\section{1.d. Martín y Marcos Carmona}

Por su parte, Martín y Marcos Carmona hermanos, hijos de españoles asentados en tierras del Pago de Magdalena, también eran dos reconocidos estancieros. El primero aparece contrayendo matrimonio con Catalina Barbosa en 1765, también hija de españoles. El segundo, asimismo, casado en 1767 con María Montes de Oca, hija de Pedro Montes de Oca y Rosa de la $\mathrm{O}$, ambos prestigiosos y reconocidos vecinos, en el ámbito de la sociedad colonial.

De los dos hermanos Carmona, quien aparece con mayor asiduidad en las fuentes es Martín y su esposa. En este sentido se los ve, a ambos, como testigos de casamiento y padrinos de bautismo en los Registros Parroquiales de Magdalena. De estos registros puede observarse la relación que los Carmona tenían con los Montes de Oca (por vìa familiar), pero también con otros hacendados reconocidos como Santiago Echeverría y los Sosa9.

Martín Carmona, por su parte, parece haber adquirido terrenos en otros pagos del ámbito rural bonaerense. Así, por ejemplo en 1811 en Lavalle, Monte Grande, en el paraje llamado El Potrerillo se mensura un terreno de propiedad de Martín Carmona que luego, en 1811 pasa a ser propiedad de Pablo Sáenz Valiente. Por otra parte, en 1815 en Chascomús, "en la parte sur del Río Salado" aparece registrado Martín Carmona en una estancia con agregados y peones ${ }^{10}$. Años más tarde se verá a sus descendientes relacionados con la familia Rosas.

9 Revista del Instituto Argentino de Ciencias Genealógicas, Nro.21, p.122 , 1987.

${ }^{10}$ CENSO de 1815 
Revista Brasileira de História \& Ciências Sociais - RBHCS

Vol. $8 \mathrm{~N}^{\circ}$ 16, Julho - Dezembro de 2016

\section{CARACTERÍSTICAS EN COMUN DE "LOS GRANDES” PRODUCTORES}

Estos hacendados considerados por este estudio como "los grandes" manifiestan ciertas características comunes.

Todos ellos forman parte de los grandes estancieros de la campaña que registran una producción diversificada, en el sentido que también se dedican a la agricultura, cuentan con mano de obra asalariada y en algunos casos con esclavos y destinan gran parte de su producción al mercado externo de cueros. Precisamente, sus características los unen con el resto de los grandes hacendados de Buenos Aires colonial, cuyas marcas también se las ve incursionar en los corrales de abasto porteño, pero a diferencia de los citados, sòlo en forma esporádica.

Los grandes hacendados de Buenos Aires se dedican fundamentalmente al mercado de cueros para la exportación y destinan sólo una porción de esa producción al mercado local, pero a diferencia de los que hemos visto acá, sus intervenciones son pequeñas siguiendo la tendencia general de este mercado. Así por ejemplo, Diego Trillo es un reconocido hacendado que participa habitualmente en el mercado de abasto de carne en el corral de Carricaburu, pero con intervenciones que no exceden las entradas de 35 reses mensuales ${ }^{11}$.

Entre otros hacendados que también envían reses al mercado de abasto, pero en proporciones pequeñas pueden mencionarse Castro, vecino hacendado del Partido de Chascomús ${ }^{12}$.

Así también Juan Miguens, Antonio Millàn, Josè Dominguez o Cascallares¹3, entre otros. Todos ellos entonces, tienen en común su participación atomizada en el mercado local, abocando en cambio la mayor parte de su productividad al mercado de cueros destinados a la exportación ${ }^{14}$.

${ }^{11}$ Sobre el tema: ALEMANO, M. E, Construcción de poder y ascenso social en una frontera colonial: el caso de Diego Trillo. En: Andes, vol.24 no.1 Salta, 2013.

12 BANZATO, G, Tierra, comercio y gobierno en el surgimiento de los pueblos bonaerenses. Juan Lorenzo Castro, hacendado, pulpero y alcalde de Chascomús,1802-1820. En: XIII Jornadas Interescuelas y Departamentos de Historia Universidad Nacional de Catamarca, Catamarca, 2011.

13 HALPERIN DONGHI,T, Revolución y guerra: formación de una élite dirigente en la argentina criolla, Ed. Siglo XXI, Buenos Aires, 1972

14Padrones de 1728, 1726, 1744. En: Documentos para la Historia Argentina, Instituto de Historia Argentina y Americana "Dr. Emilio Ravignani", Facultad de Filosofía y Letras; Tomos X, XI y XII, Buenos Aires, 1913. 


\section{Revista Brasileira de História \& Ciências Sociais - RBHCS}

Vol. $8 \mathrm{~N}^{0}$ 16, Julho - Dezembro de 2016

Sólo unos pocos, van a aparecer en forma sistemática y consolidada en el mercado local. Todos ellos, Gabriel Rocha, Januario Fernández, Bartolomé Villoldo y los hermanos Carmona, Martín y Marcos, tienen en comùn su antigüedad de asentamiento, su arraigo en la comunidad de origen, el hecho de ser hacendados de "vieja data". Todos los que hemos detectado en las fuentes pertenecen a partidos que en la etapa tardo-colonial ya se encuentran consolidados Estos hacendados poseen una posición arraigada, con estrechos lazos amicales y parentales con otros hacendados o antiguos pobladores españoles, la mayoría ha logrado influencias o ha participado de instancias políticas comunales y cuentan con márgenes de movimiento económico con mayor experiencia que quienes van surgiendo en los partidos de nuevo asentamiento. Estas características les van a permitir, entonces, dedicar una buena parte de su producción ganadera al mercado local como complemento de su interés en el mercado de cueros.

\section{GRANDES COMERCIANTES INTERMEDIARIOS: LOS ABASTECEDORES O CORRALEROS}

En cuanto a los abastecedores o reseros también los registros muestran, para todo el último cuarto del siglo XVIII, una escena similar a la de los productores, predominio de pequeñas transacciones que manifiesta una preeminencia de pequeños comerciantes intermediarios en el ámbito de la carne vacuna para consumo.

También en este caso nos encontramos con un promedio de 25,6 vacunos mensuales per capita vendido a los corrales, lo que indicaría un promedio diario de 0,8 reses diarias por abastecedor. Asimismo, se observa que el $87,4 \%$ de estos abastecedores aparece enviando mensualmente menos de 50 vacunos al mercado. Por su parte, los "grandes" abastecedores, llamados así porque venden más de 100 reses mensuales, conforman un porcentual proporcionalmente menor, puesto que representan el 1,4\% del total de abastecedores que destinan ganado vacuno al abasto de Buenos Aires. Esto puede verse en el siguiente cuadro: 


\section{Cuadro II}

Distribución de frecuencia de reses mensuales ingresadas por los abastecedores (1776 1786)

\begin{tabular}{|l|l|l|l|l|}
\hline Años & $\begin{array}{l}\text { O-49 reses } \\
\text { Porc. }\end{array}$ & $\begin{array}{l}50-99 \text { reses } \\
\text { Porc. }\end{array}$ & $\begin{array}{l}\text { 100-149 } \\
\text { reses } \\
\text { Porc. }\end{array}$ & $\begin{array}{l}+ \text { de 150 } \\
\text { reses Porc. }\end{array}$ \\
\hline 1776 & $89,6 \%(165)$ & $4,3 \%(8)$ & $3,3 \%(6)$ & $2,8 \%(5)$ \\
\hline 1777 & $86,7 \%(228)$ & $9,5 \%(25)$ & $2,3 \%(6)$ & $1,5 \%(4)$ \\
\hline 1778 & $88,6 \%(125)$ & $15,5 \%(25)$ & $4,9 \%(8)$ & $2,5 \%(4)$ \\
\hline 1779 & $87,6 \%(162)$ & $10,3 \%(19)$ & $2,1 \%(4)$ & $0,5 \%(1)$ \\
\hline 1780 & $75 \%(132)$ & $17 \%(30)$ & $5,7 \%(10)$ & $2,3 \%(4)$ \\
\hline 1781 & $91,5 \%(206)$ & $5,8 \%(13)$ & $1,8 \%(4)$ & $0,9 \%(2)$ \\
\hline 1782 & $86 \%(166)$ & $9,3 \%(18)$ & $3,6 \%(7)$ & $1 \%(2)$ \\
\hline 1783 & $86 \%(157)$ & $9,6 \%(18)$ & $4,8 \%(9)$ &, $1 \%(4)$ \\
\hline 1784 & $96,3 \%(310)$ & $3,1 \%(10)$ & $0,3 \%(1)$ & $0,3 \%(1)$ \\
\hline 1785 & $87,3 \%(200)$ & $10 \%(23)$ & $1,7 \%(4)$ & $0,9 \%(2)$ \\
\hline 1786 & $90,7 \%(234)$ & $5,8 \%(15)$ & $1,9 \%(5)$ & $1,5 \%(4)$ \\
\hline Total & $\begin{array}{l}87,4 \% \\
(2085)\end{array}$ & $8,5 \%(204)$ & $2,7 \%(64)$ & $1,4 \%(33$ \\
\hline
\end{tabular}

Fuentes: AGN, Sala IX, 20-1-3.

Entonces, al igual que en el caso de los productores, son algunos pocos comerciantes intermediarios los que ingresan más de 100 reses mensuales considerados en este estudio como los "grandes". En este caso, nos encontramos con la presencia de un conjunto de actores sociales relacionados entre sí como Berrnardo Lara, José Rivadeneyra y Bernardo y Eugenio Montes de Oca. Estos abastecedores figuran, asimismo, como grandes comerciantes de la ciudad de Buenos Aires.

\subsection{Bernardo Lara}

Los Lara conforman una antigua familia de estancieros del partido de Magdalena ${ }^{15}$, siendo además propietarios de grandes extensiones de tierra. Su padre, Agustìn Lara, era un importante hacendado (español) de Magdalena, quien en 1726 aparece consignado en

15 Las esclavas y esclavos de Agustín Lara aparecen consignados en los Registros Parroquiales de Magdalena en 1755 y 1757 bautizando a sus hijos. 


\section{Revista Brasileira de História \& Ciências Sociais - RBHCS}

Vol. $8 \mathrm{~N}^{\circ}$ 16, Julho - Dezembro de 2016

el padrón del partido con estancia propia, esclavos y cuatro hijos, uno de ellos Bernardo de 20 años y Agustín más pequeño.

Agustín Lara (padre), por su parte, es vecino y amigo de la familia Montes de Oca, la familia De la Cruz y los Rivadeneyra, todos ellos hacendados, comerciantes y "sacadores de reses" para el mercado de abasto de Buenos Aires ${ }^{16}$.

Bernardo Lara, por su parte, aparece como un importante abastecedor del corral de Carricaburu con casa propia y familia en el barrio de abastecedores en Quilmes. Igualmente lo encontramos como propietario de una estancia en el Partido de Magdalena, frente al paraje de Ensenada de Barragán.

Cabe aclarar que esta doble calidad de productor y abastecedor aparecería en los registros como una excepción. También se lo ve en el Registro de casamientos de Quilmes contrayendo matrimonio con Petrona Rodriguez, quien a su vez es hija de Clemente Rodriguez y María Josefa Alvarado, ambos pertenecientes a familias de hacendados del pago de Magdalena.

Asimismo, las redes parentales de la familia Lara se extendían a otros abastecedores y productores del mercado de abasto. En este sentido puede verse que la esposa de Bernardo Lara, Petrona Rodríguez, era hija de otro importante estanciero Clemente Rodríguez y de Lucía Alvarado, esta última tía de otro abastecedor destacado, Blas Alvarado, censado en el barrio conocido como de los "sacadores de reses". Ambos, Bernardo Lara y Blas Alvarado, asimismo, eran vecinos en el barrio de "abastecedores". A su vez, Bernardo era vecino de otro gran hacendado que también actúa como abastecedor del mercado local a través del corral de Carricaburu, Bernardo Montes de Oca. Este último de igual forma, era otro de los grandes comerciantes-intermediarios que realizaba importantes transacciones en este corral, puesto que registra un promedio de 298 reses mensuales. Asimismo, entre los primos de Bernardo Lara figuran Miguel de Lara, que aparece registrado como abastecedor del corral del sur y Fernando y Juan Joseph Lara, ambos estancieros y productores de Magdalena.

Finalmente, Bernardo Lara se manifiesta, en las fuentes, como uno de los compradores de ganado de la estancia de Lopez Osornio y se lo ve en otras transacciones de ganado

16 Padrón de 1744. En: Documentos para la Historia Argentina, Instituto de Historia Argentina y Americana... ob.cit, 


\section{Revista Brasileira de História \& Ciências Sociais - RBHCS}

Vol. 8 No $^{\circ}$ 16, Julho - Dezembro de 2016

que rondan entre 600 y 700 reales. Dichos ganados están compuestos por terneras y vacunos jóvenes que son rechazados en el corral por su bajo peso ${ }^{17}$. Las entradas de vacunos registradas en el corral de Carricaburu de Bernardo Lara arrojan un promedio anual de 218 reses.

También Agustín Lara (hijo del español homónimo y hermano de Bernardo) está inscripto como abastecedor arrojando un 1 promedio de 165 reses anuales. En los registros de abasto se evidencia como uno de los pocos "grandes" productores de ganado destinado al mercado local, aunque en algunas ocasiones también se encuentra, como en el caso que estamos estudiando, consignado .como señaláramos- como abastecedor.

\subsection{José Rivadeneyra}

En el caso de José Rivadeneyra se destacaba por su sistematicidad en el ingreso de grandes cantidades de vacunos al corral de Carricaburu. La familia Rivadeneyra era una de las más antiguas de Buenos Aires, con grandes extensiones de tierras desde principios del Siglo XVII, incluyendo en ellas una merced otorgada sobre las márgenes de la laguna de Chascomús. Además fue uno de los mayores comerciantes de la plaza porteña. También vemos su apellido relacionado, en años más tarde de la época rosista, en otros partidos como el de Pila (que se funda en 1839), con su parentela instalada en tierras nuevas de la frontera rural bonaerense.

Específicamente para el caso del abasto local Rivadeneyra aparece registrado en 1760 como "carnicero", casado con Doña Juana de Sueldo quien era viuda de otro destacado abastecedor, Gerónimo Gaete. Más tarde dejará de estar registrado como carnicero y en cambio se distinguirá por ser uno de los grandes abastecedores de ganado al mercado local. De hecho, al hacer un análisis cuantitativo, en el periodo de 1776 a 1786 se puede observar que su promedio de ingreso anual al mercado de abasto era de 363 reses anuales, media relacionalmente alta sobre todo si lo compara con la media general de 231,4 reses anuales por corral (ver cuadro II del capítulo anterior). Por otra parte, el mismo no sólo aparece con el título de Don sino que además se encuentra registrado como dueño de una chacra y una estancia en el Partido de las Conchas.

${ }_{17}$ Fuente: AGN- Sucesiones, 7626. ps-15-16 


\section{Revista Brasileira de História \& Ciências Sociais - RBHCS}

Vol. 8 No $^{\circ}$ 16, Julho - Dezembro de 2016

Asimismo, en 1787 se halla en el registro oficial de los reseros o abastecedores pertenecientes al corral del Centro o Carricaburu. Allí se lo consigna como casado y con casa en la ciudad y como vecino de otros destacados abastecedores como Bernando Lara o Francisco Montes de Oca.

\subsection{Bernardo y Eugenio Montes de Oca}

Otros importantes abastecedores, como señalamos, fueron Bernardo y Eugenio Montes de Oca, hijos del capitán Pedro Montes de Oca y Doña Tomasa Lozano. Su padre, Pedro Montes de Oca fue un importante hacendado del partido de Magdalena y su abuelo fue el alférez Antonio Martín Montes de Oca.

Bernardo aparece registrado en la ciudad de Buenos Aires como un reconocido "sacador de reses”, emparentado a su vez con Juan Anselmo Echeverría, importante hacendado de Magdalena y corralero del Cabildo.

Eugenio Montes de Oca también constituye un destacado comerciante de Buenos Aires y figura en el registro de abastecedores como otro "sacador de reses".

Asimismo, ambos hermanos, Bernardo y Eugenio, aparecen emparentados con importantes familias de hacendados de Magdalena como los Gil, los Negrete, Troncoso, Hornos, Barragán. Y específicamente en la ciudad de Buenos Aires se los ve relacionados con familia de otros importantes abastecedores como De la Cruz y Avalos de Mendoza. Todos ellos nucleados dentro del barrio de "sacadores de reses, faenadores y comerciantes de carnes del Sur porteño”.

Por su parte, Bernardo Montes de Oca y su esposa se encuentran, recurrentemente, en los Registros Parroquiales de Quilmes como testigos de casamiento o bien padrinos de bautismos relacionados con familias de otros "sacadores de reses" como Luis Gutiérrez o Felix De la Cruz, entre otros.

\section{CARACTERÍSTICAS EN COMUN DE LOS GRANDES INTERMEDIARIOS -} ABASTECEDORES

Otros abastecedores relacionados directamente con el mercado local, comerciantes locales pero, a diferencia de los anteriores, sin conexión con el mercado externo reconocidos fueron Atanasio Alvarado, Juan y Thomás Sosa y Vicente Gesala. 


\section{Revista Brasileira de História \& Ciências Sociais - RBHCS}

Vol. 8 No $^{\circ}$ 16, Julho - Dezembro de 2016

En las fuentes analizadas Atanasio Alvarado registra un promedio de 228 reses anuales y su primo Blas Alvarado se encuentra consignando una media de 386 vacunos. Ambos, aparecen en los registros oficiales de abastecedores o reseros de la ciudad de Buenos Aires formando parte del grupo ya consolidado con un status formal de comerciantesintermediarios que abastecían de reses al corral de Carricaburu. Por lo que puede deducirse de las fuentes, ambos estaban asentados con sus familias al norte de la ciudad de Buenos Aires en San Isidro.

No obstante todo aquello Blas Alvarado figuraba como casado en 1767 con Jerónima Mitre en los registros de la Iglesia de Nuestra Señora de la Concepción de los Quilmes a la que pertenecía todo el pago de la Magdalena. Allí se consigna a Blas como hijo de Don Miguel Gerónimo de Alvarado y doña Catalina Gomez Herrera. Su esposa a su vez, es hija del español Bernardo José Mitre. Como todo vecino reconocido, figuraba en los registros parroquiales de San Isidro como testigo o padrino de bautismos y casamientos de muchos parroquianos. Cabe aclarar asimismo, que el padre de Blas Alvarado era hijo a su vez de uno de los integrantes de la familia de los López Osornio, pertenecientes a una de los clanes más influyentes en el ámbito rural porteño pues eran poseedores de grandes extensiones de tierras en todos los pagos que rodeaban la ciudad, incluyendo el pago de la Magdalena.

De manera entonces puede verse a Blas Alvarado junto con Atanasio Alvarado como conformando ese grupo de comerciantes intermediarios que conectan la ciudad con el ámbito rural a través de la recogida de ganado vacuno con destino a la comercialización local. Asimismo, todos ellos parecen tener fuertes contactos entre sí y habitan en ámbitos barriales cercanos a los respectivos corrales. Cabe aclarar asimismo, que no puede detectarse un grupo de productores determinado para estos abastecedores.

Por su parte Juan y Thomás Sosa, parecen ser oriundos de Magdalena. El primero aparece consignado en el registro de abastecedores del corral de Carricaburu, asentado en la ciudad de Buenos Aires junto a su esposa y "con casa propia”. El promedio de reses ingresado anualmente por Juan Sosa, es de 50 vacunos anuales, lo que ubicaría a este dentro del grupo de los pequeños comerciantes-intermediarios. Por su parte, Thomás Sosa, registraba un promedio anual de 164 reses y parece ser un vecino reconocido en la recientemente fundada Guardia de Chascomús, en el pago de la Magdalena. Asimismo, 


\section{Revista Brasileira de História \& Ciências Sociais - RBHCS}

Vol. $8 \mathrm{~N}^{\circ}$ 16, Julho - Dezembro de 2016

su presencia era recurrente en los registros parroquiales del partido como padrino de muy diversos bautismos y casamientos.

Finalmente también Vicente Gesala pertenecía al grupo de abastecedores que figuraba en las listas oficiales, era vecino en la ciudad y residía junto a otros abastecedores destacados como Cayetano Lozano, Bartolomé Angulo y Bernardo Gómez, quién además era su suegro.

Aquellos abastecedores conforman, entonces, un sector de comerciantes intermediarios que se encuentra mayoritariamente instalados en la ciudad y respecto de los cuales, aunque no podamos precisar en forma clara sus características como grupo, si podemos establecer que están en contacto permanente y conformando un sector unido por relaciones de vecindad o parentesco. No sólo poseen una actividad común que los unifica como categoría ocupacional, sino que además son vecinos próximos y nuclean un grupo con fuertes lazos parentales y amicales, testimoneado en los casamientos y padrinazgos registrados en los Registros Parroquiales. Puede deducirse así, que estos grandes productores y abastecedores constituyen un núcleo endogámico.

Un grupo reducido de grandes hacendados a su vez, combina la venta al mercado externo de cueros con el envío de ganado en pie al mercado de abasto de Buenos Aires. Sólo por excepción, como es el caso de Bernardo Lara, ejercen simultáneamente la función de producción y venta de ganado al mercado.

Finalmente cabe agregar que su presencia es sentida por los pequeños abastecedores, cuyas quejas aparecen reflejadas en las Actas de Cabildo. Quejas que muestran una situación de asimetría. Los grandes parecen tener prioridad sobre los pequeños en la entrada de ganado a los corrales de abasto.

“... nos sucede muchas veces, que trayendo ganado a los corrales no se mata, ni se consume, sin embargo que entra de los primeros; y posponiendo el nuestro, pasan a otro que posteriormente llega. Con este motivo sufrimos indecibles prejuicios, porque obligados de la necesidad, nos vemos en la precisión de rogar a los compradores (cosa a la verdad increíble) para que por ínfimo precio nos reciban las carnes y contribuyan tal vez, lo que gusten. De aquí resulta que después de un dilatado tiempo que tenemos el ganado encorralado, y por no perderlo todo lo damos en baja estimación, perdiendo de los principales. Resulta también, que como experimentamos aquellos quebrantos, nos encontramos con facilidad quien nos habilite para 


\section{Revista Brasileira de História \& Ciências Sociais - RBHCS}

Vol. $8 \mathrm{~N}^{0}$ 16, Julho - Dezembro de 2016

otros iguales negocios; y así el Público y nuestras desgraciadas familias padecen y sienten semejantes males y extorsiones" (ACTAS DEL EXTINGUIDO CABILDO, 1913, p.154-155). Se puede concluir que el mercado de abasto de carne estructuralmente atomizado y disperso, con predominio de pequeños y medianos productores y abastecedores incluye en su seno a un sector fuerte de "grandes abastecedores y productores" que se destacan y se identifican del resto por su densidad como grupo y su vinculación con el mercado externo.

\section{LOS MERCADOS: LA CIUDAD FRENTE AL MERCADO EXTERIOR}

Estos grandes hacendados-productores y abastecedores- comerciantes muestran la relación de complementariedad entre el mercado local y aquel que tiene su mirada en el exterior en esta etapa tardo-colonial. Y si nos referimos puntualmente a la producción ganadera de Buenos Aires, aparece en escena la venta de cueros a través del puerto de la ciudad homónima, que desde el siglo XVII primero ilegalmente y a partir de las Reformas Borbónicas en forma abierta, exporta esos bienes a la metrópoli española y otras naciones industrializadas ${ }^{18}$.

Sin duda, desde el siglo XVII la economía de la ciudad de Buenos Aires estuvo sistemáticamente vinculada al mercado alto-peruano con centro en Potosí por medio de la introducción, a través de su puerto, de productos de Castilla y la exportación de metales preciosos que se complementaba con productos ganaderos, especialmente cueros. El eje Potosí- Buenos Aires permanecerá activo hasta el momento en que comienza la etapa independiente dando vida a una región que articula un amplio espacio en función de una amplia red de circuitos mercantiles que alimentan, en forma simultánea, el comercio alto-peruano y la demanda externa de metales preciosos y productos pecuarios, a través del Atlántico. Aquello trajo como consecuencia la consolidación de un importante sector de comerciantes intermediarios entre el mercado ultramarino y los mercados locales, así como un crecimiento sistemático, en el ámbito rural vinculado a ese eje, de la producción de bienes agrícola-ganaderos. De esta manera,

${ }_{18}$ Cabe señalar que Buenos Aires junto al Litoral rioplatense ha sido desde el siglo XVII importante productora de productos pecuarios y una de las principales proveedoras de esos bienes para el mercado transatlántico. Dicho Litoral, llamado comúnmente Mesopotamia, se encuentra situado entre los ríos Uruguay y Paraná y posee una relación directa con la ciudad-puerto. 


\section{Revista Brasileira de História \& Ciências Sociais - RBHCS}

Vol. $8 \mathrm{~N}^{0}$ 16, Julho - Dezembro de 2016

Buenos Aires, ciudad que constituye el punto de anclaje de los intercambios mercantiles, comienza a crecer, fundamentalmente a mediados del siglo XVIII, conformándose en una importante urbe con una demanda de bienes y servicios que va estructurando un mercado local vital y próspero que atiende a una demanda creciente.

Por su parte, el comercio de exportación va creciendo, primero a través del contrabando y luego, con las Reformas Borbónicas de 1778, cada vez más abiertamente bajo el sistema de "libre comercio"19.

Esto a su vez genera un importante crecimiento demográfico vegetativo y migratorio que viene a incrementar y diversificar la demanda de productos básicos para su alimentación.

Respecto a la relación del Río de la Plata en la etapa colonial con los mercados ultramarinos Fernando Jumar señala: “... la región Río de la Plata debe ser considerada bajo cuatro aspectos. En primer lugar, como punto de contacto entre los mercados hispanoamericanos y extra-hispanoamericanos, tanto americanos como ultramarinos. En segundo lugar, en tanto que región cuyas sociedades consumen parte de los bienes importados. En tercer lugar, como poseedora de un complejo productivo regional que le permitió volcar excedentes en los mercados americanos (hispanos o no) y ultramarinos. Y, en cuarto lugar, como proveedora de bienes y servicios necesarios para la existencia misma del comercio a corta, larga y muy larga distancia” (JUMAR, 2012, p. 123-124) . Señala asimismo, que el comercio con los mercados ultramarinos ha sido determinante también en la conformación de una economía local, donde precisamente los mercados locales condicionan el desarrollo de un sector con intereses locales, “... actores arraigados que mantendrían relaciones no exentas de conflicto con los aglutinados exclusivamente en torno del comercio ultramarino del sistema legal español, primordialmente asociados a intereses externos al espacio" (JUMAR, 2012, p.126-127).

Estos fenómenos coinciden con el comienzo del debilitamiento en la etapa tardo-colonial y la ruptura definitiva en la etapa independiente, del eje Potosí-Buenos Aires, a partir de la reestructuración administrativa que impone la metrópoli. En este sentido, a mediados del siglo XVIII Buenos Aires junto con el Litoral rioplatense adquirirán una creciente autonomía que la ubicarán en el centro y como principal protagonista del mercado

19 SCHMIT, R y ROSAL, M, En: Las exportaciones pecuarias bonaerenses y el espacio mercantil rioplatense (1768-1854), en: FRADKIN,R y GARAVAGLIA,J,C, En busca de un tiempo perdido. La economía de Buenos Aires en el "país de la abundancia", 1750-1865, Prometeo Libros, Buenos Aires, 2004. 


\section{Revista Brasileira de História \& Ciências Sociais - RBHCS}

Vol. $8 \mathrm{~N}^{0}$ 16, Julho - Dezembro de 2016

atlántico ${ }^{20}$. En este contexto, la carne vacuna será uno de los alimentos fundamentales en la dieta de la población urbana en crecimiento y el mercado de abasto que la nutre se estructurará como complemento de ese crecimiento económico que trae de la mano el viraje definitivo de Buenos Aires hacia el mercado exportador, donde los productos pecuarios irán desplazando muy lentamente a los metales. En este sentido, en el ámbito de la producción, los bienes pecuarios adquirirán un protagonismo cada vez mayor conforme se acerqué el periodo independiente, lo que acelerará y estimulará el fenómeno de la expansión ganadera.

De esta forma, cueros y tasajo para la exportación, carne para el abasto local, aparecen como complementarios y con una incidencia similar en la estructuración de una economía en constante progreso.

La importancia del mercado de abasto de carne a la ciudad de Buenos Aires estaría dada, precisamente, en ese carácter de complementariedad y sustento de una estructura económica más amplia dependiente del exterior, fenómeno que irá gestando y moldeando la forma que tendrá en su historia futura y perdurará hasta nuestros días.

\section{A MODO DE CONCLUSION}

En resumen, los actores "grandes" del mercado de abasto (quienes ingresan más de 100 150 reses mensuales) aparecen claramente identificados en la fuente como hacendados y comerciantes reconocidos en su comunidad. Entre los grandes productores pueden mencionarse a Januario Fernández, Bartolomé Villoldo y los hermanos Carmona, Martín y Marcos entre otros. Quienes se destacan como "vecinos" hacendados con el título de "don", cuentan con mano de obra dependiente (esclava y/o libre), una producción diversificada y una dedicación sistemática al mercado citadino de carne vacuna, aún cuando la mayor parte de su producción está abocada al mercado externo. De modo que matizan ambos mercados al momento de destinar su producción ganadera.

Por su parte, entre los "grandes abastecedores” podríamos nombrar a José Rivadeneira,

${ }^{20}$ A lo largo de la primera mitad del siglo XVIII los cueros nunca constituyeron menos del $60 \%$ de las exportaciones, en valor, muy frecuentemente proporcionaban más del $70 \%$ de ese total. El resto estaba constituido en buena parte por exportaciones complementarias de las de cuero: otros productos de la industrialización del vacuno, básicamente carne salada y sebo, pero también por otros productos de valores mucho menores como astas, hueso para botones y para abono. 


\section{Revista Brasileira de História \& Ciências Sociais - RBHCS}

Vol. 8 No $^{\circ}$ 16, Julho - Dezembro de 2016

Bernardo Lara, Bernardo y Eugenio Montes de Oca, Blas y Tomás Alvarado. Grupo acotado intermediario entre ciudad y campaña que se dedica -a diferencia de los grandes productores- fundamentalmente al mercado local. Se caracteriza por poseer entre ellos lazos amicales y matrimoniales que le imprimen un carácter de homogeneidad al grupo. Ambos, grupos entonces, productores y abastecedores, cada uno en el eslabón del circuito de producción-comercialización de carne vacuna para consumo, se muestran como grupos endogámicos, que probablemente pertenezcan a un sector social acomodado con ciertos anclajes y ventajas en el poder comunal y con una relación directa, en el caso de los productores e indirecta, en el caso de los abastecedores, con las instancias del comercio ultramarino. Denominados "grandes" en este trabajo en términos relativos, en la medida que tienen posibilidad de manejar sistemáticamente màs de 100 reses mensuales para producir y comercializar en el abasto porteño. Grandes en términos de productores, en la medida en que cuentan con capital económico que les permite contar con mano de obra esclava o asalariada. Grandes en el sentido de que poseen capital social que los muestra como vecinos prestigiosos dentro de su comunidad. Y respecto a los abastecedores, "grandes" en la medida que se incluyen entre aquellos comerciantes destacados en el ámbito de la ciudad porteña, poseen importante capital económico y un capital político que les permite cierto poder de negociación del que están exentos los pequeños comerciantes coloniales.

Estos "grandes" nos llevan a matizar la imagen de un mercado predominantemente atomizado y diversificado, dándonos en cambio, la representación de un mercado en el que si bien los pequeños y medianos tienen en sus manos la producción y las transacciones mercantiles, hay un sector reducido pero cualitativamente importante, de vecinos hacendados y comerciantes, que incursiona en èl y contribuye con su desarrollo.

BIBLIOGRAFIA GENERAL

ALEMANO, M, Construcción de poder y ascenso social en una frontera colonial: el caso de Diego Trillo, Andes vol.24 no.1, 2013

BANZATO, G, Tierra, comercio y gobierno en el surgimiento de los pueblos bonaerenses. Juan Lorenzo Castro, hacendado, pulpero y alcalde de Chascomús, 1802-182o. En: XIII Jornadas Interescuelas y Departamentos de Historia Universidad Nacional de Catamarca, 2011. 
Revista Brasileira de História \& Ciências Sociais - RBHCS

Vol. 8 No $^{\circ}$ 16, Julho - Dezembro de 2016

CUESTA,M, Precios, población, impuestos y producción. La economía de Buenos Aires en el siglo XVIII. Buenos Aires, Temas Grupo Editorial, 2009.

DUPUY, A , Mercado de abasto de carne en Buenos Aires colonial (siglos XVIXVIII), Cambios y continuidades, Madrid, Editorial Académica Española, 2013.

FRADKIN, R -GARAVAGLIA, J.C, (ed.), En busca de un tiempo perdido. La economía de Buenos Aires en el país de la abundancia 1750-1865, Buenos Aires, Prometeo libros, 2004

GARCIA, J. A, Abastos de la ciudad y compañía de Buenos Aires, 1773-1809, Facultad de Filosofía y Letras, Universidad de Buenos Aires, XV, 1914.

GELMAN, J, Campesinos y Estancieros. Una región del Río de la Plata a fines de la época colonial, Buenos Aires, Editorial Los Libros del Riel, 1998.

HALPERIN DONGHI, T, (1972), Revolución y guerra, formación de una élite dirigente en la argentina criolla, Buenos Aires, Ed. Siglo XXI.

JUMAR, F- KRASELSKY, J, (2007), Las esferas del poder. Hacendados y comerciantes ante los cambios de la segunda mitad del siglo XVIII, Anuario del Instituto de Historia Argentina, FAHCE - UNLP, La Plata, vol. 7 p. $31-58$

QUIROZ,E Entre el lujo y la subsistencia. Mercado, abastecimiento y precios de la carne en la ciudad de México, 1750-1812, Instituto de Investigaciones Dr. José M. Luis Mora, México, Colegio de México, 2005

MAYO,C, Estancia y sociedad en la Pampa 1740- 182o, Bs. As, Ed. Biblos, 1995

FUENTES:

\section{EDITAS}

Actas del Extinguido Cabildo, sección: Abastos, 20-7-170:1773.

Padrones de 1728, 1726, 1744" en: Documentos para la Historia Argentina, Instituto de Historia Argentina y Americana "Dr. Emilio Ravignani" · Facultad de Filosofía y Letras; Tomos X, XI y XII

Revista del Instituto Argentino de Ciencias Genealógicas, Nro.21, Bs. As.p.222

INEDITAS

Archivo General de la Naciòn, (AGN), Sala IX, 20-1-3

AGN, Sala IX, 9-7-7- Comandancia de Fronteras de Pergamino, ( 1766-1808) 
Revista Brasileira de História \& Ciências Sociais - RBHCS

Vol. $8 \mathrm{~N}^{0}$ 16, Julho - Dezembro de 2016

AGN, Sala IX 9-7-7, Padrones de la ciudad y campaña, (1782-1807).

AGN, Sucesiones 7626-ps-15-16.

Recebido em Outubro de 2016

Aprovado em Dezembro de 2016 